\title{
A New and Practical Method to Locate Point ANS - A Cephalometric Study
}

\author{
Pallavi Diagavane ${ }^{1}$, Priyanka Niranjane ${ }^{2}$, Puneet Batra ${ }^{3}$, Ranjit Kamble ${ }^{4}$, Bhagyashri Chimote ${ }^{5}$ \\ ${ }^{1}$ Department of Orthodontics and Dentofacial Orthopaedics, Sharad Pawar Dental College, Sawangi, \\ Maharashtra, India. ${ }^{2}$ Department of Orthodontics and Dentofacial Orthopaedics, Sharad Pawar Dental \\ College, Sawangi, Maharashtra, India. ${ }^{3}$ Department of Orthodontics, IDST, Modinagar Uttar Pradesh, \\ India. ${ }^{4}$ Department of Orthodontics and Dentofacial Orthopaedics, Sharad Pawar Dental College, \\ Sawangi, Maharashtra, India. ${ }^{5}$ Department of Prosthodontics, VYWS, Amravati, Maharashtra, India,
}

\section{ABSTRACT}

\section{BACKGROUND}

Diagnosis and treatment planning in skeletal discrepancy and disorders requires radiographic assessment. Disturbance in growth and development alters the morphologic build-up of bony structures, which makes evaluation difficult. Out of these skeletal landmarks Point ANS is seen affected in many conditions like cleft lip and palate, Binders Syndrome, Down's Syndrome, nasomaxillary hypoplasia, etc., wherein maxilla is mostly affected. Surgical intervention if required needs exact evaluation of point ANS. The purpose of the present study is thus to revisit Point ANS to aid in the cephalometric evaluation in cases where location of Point ANS is difficult; thus, making treatment planning easy.

\section{METHODS}

50 lateral cephalograms were evaluated by taking reference of skeletal landmarks and linear measurements were done.

\section{RESULTS}

Linear measurements from Point Ptm'-Ba', Ba'-ANS', ANS'-A were found to be proportionally equal with a ratio of 1:1:1.

\section{CONCLUSIONS}

Linear distance of Point ANS to N perpendicular (ANS') line was approximately half of the linear distance of Point Ba'-A, while Point ANS is placed approximately $5 \pm 2 \mathrm{~mm}$ ahead of the line $\mathrm{N}$ perpendicular.

\section{KEY WORDS}

ANS, Cleft, Cephalogram
Corresponding Author: Dr. Pallavi Diagavane, Reader,

Department of Orthodontics \& Dentofacial Orthopaedics, Sharad Pawar Dental College, Sawangi, Maharashtra, India. E-mail: drpallavi_ortho@rediffmail.com

DOI: $10.14260 /$ jemds/2020/468

How to Cite This Article:

Diagavane $P$, Niranjane $P$, Batra $P$, et al. A new and practical method to locate point ANS - a cephalometric study. J. Evolution Med. Dent. Sci. 2020;9(30):2148-2150, DOI: $10.14260 /$ jemds/2020/468

Submission 06-03-2020,

Peer Review 15-06-2020,

Acceptance 22-06-2020,

Published 27-07-2020.

Copyright (C) 2020 JEMDS. This is an open access article distributed under Creative Commons Attribution License [Attribution 4.0 International (CC BY 4.0)] 


\section{BACKGROUND}

Radiographs are vital diagnostic tool to analyse any case for diagnosis and treatment planning in any field of medicine. Orthodontic and surgical interest in cephalometric assessment of hard and soft tissue of head and face and the zest for exact identification and location of the landmarks has led to invention of newer technologies from 2D x-ray machines to 3D and CBCT, laser scanner and much more for identification of bony and soft tissue landmarks.

Though identification of skeletal, dental and soft tissue landmarks is essential, it is difficult to locate them on routine radiographs due to the extreme range or radiolucency between bone and soft tissue. Various refined resources are made available, but these tools are helpful only if the skeletal and dental landmarks can be easily identified and only if they are not disturbed due to altered growth and development.

Literature has shown that there are landmarks which have been revisited due to the quest of their exact identification and location. ${ }^{1}$ Among all landmarks, conflicting anatomical details and conceptual judgment is also seen with point ANS (Anterior Nasal Spine) which is a bony projection in the skull, the anterior most point of the maxilla at the level of palate 2 . Medially, the anterior surface of the maxilla is limited by a deep concavity, the nasal notch, the margin of which gives attachment to the dilator naris posterior and ends below in a pointed process, which with its fellow on the opposite side forms the anterior nasal spine.

Certain craniofacial anomalies like cleft lip and palate (mostly unilateral), ${ }^{3}$ Crouzon's syndrome, ${ }^{3}$ naso maxillary hypoplasia (binder's syndrome), ${ }^{4}$ silent sinus syndrome, ${ }^{5}$ Downs syndrome, ${ }^{6}$ first and second brachial arch syndrome, ${ }^{7}$ cleidocranial dysostosis, Treacher Collins syndrome, ${ }^{8,9}$ etc, make it difficult to identify the landmarks on cephalometric radiographs. Therefore, the anteroposterior dimensions of the maxilla are difficult to evaluate.

Almost all surgical and orthodontic cephalometric analysis use point ANS. If not identified, this can affect the surgical outcome if procedures like anterior maxillary distraction, osteotomy, Le Fort are planned to correct the discrepancies in cleft lip and palate, nasomaxillary hypoplasia and other anomalies with deficient maxilla.

In instances where point ANS is not identified, another means should be sought to judge the location of this point. The purpose of the present study is thus to identify point ANS with acceptable accuracy and ease.

\section{METHODS}

50 lateral cephalometric radiographs already available in the departmental record data were collected for the patients who visited the department and were treated between January to December 2019. The cephalographs of 31 male and 19 female who had completed their craniofacial growth i.e. between 19$21 \pm 2$ years age (mean age 20.4 years), with skeletal class I i.e. ANB $2^{\circ} \pm 2^{\circ}$ were evaluated. Cephalograms of patients with craniofacial anomaly, skeletal discrepancy like vertical maxillary excess, mandibular and palatal plane rotations, and history of craniofacial and skeletal surgeries were excluded. For standardization all lateral cephalometric radiographs were taken by one technician on cephalometric $\mathrm{x}$-ray machine (Planmeca Prolineec, SN-XEC425478).

Radiographs were traced on 0.03 -inch lead acetate sheet with 2B lead pencil. For evaluation skeletal landmarks taken into considerations were Point N (Nasion), Point S (Sella Turcica), Point Ptm (lower most tip of the Ptm), Point Ba (Basion), Point A, Point ANS.

A horizontal plane $7^{\circ}$ above the cranial base (SN plane) was drawn, a perpendicular was drawn to this plane from Point $\mathrm{N}$ as $\mathrm{N}$ perpendicular. Perpendicular was drawn from Point Ptm, Point Ba, Point ANS and Point A to $\mathrm{N}$ perpendicular and marked respectively. Now on the line $\mathrm{N}$ perpendicular we have 4 points Ptm', Ba', ANS', A' (Fig 1)

Linear vertical measurements were done from Point Ptm'Ba', Ba'-ANS', ANS'-A', and also linear horizontal measurement was done for point ANS-ANS' on N perpendicular.

\section{Statistical Analysis}

Inter-operator error was determined. To minimize the error, all radiographs were retraced and assessed on two occasions at the interval of three weeks by second and third authors at different times. The variance ratio and kappa tests were used to determine the reliability of measurements. The average for all the parameters was obtained individually.

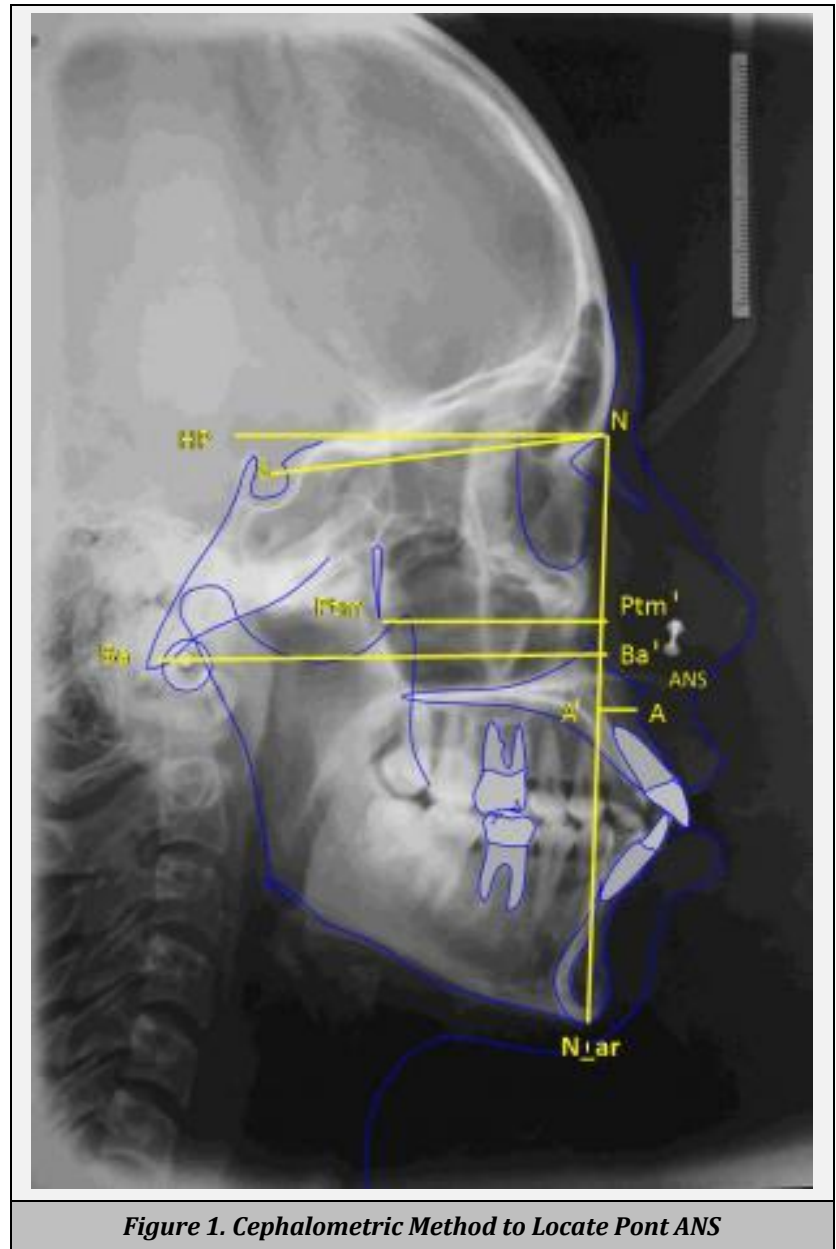


RESULTS

On evaluation of the lateral cephalographs as mentioned in the inclusion criteria for the selection of only class I cases the mean ANB angle was found to be $2.16^{\circ}$ which can be taken as $2-3^{\circ}$ suggestive of skeletal class I. The mean Ptm'-Ba' vertical length was $6.11 \mathrm{~mm}$ which can be taken as $6 \mathrm{~mm}$, Ba'-ANS' vertical was $6.39 \mathrm{~mm}$ which can be taken as $6 \mathrm{~mm}$, ANS'-A' was $5.81 \mathrm{~mm}$ which can be again taken as $6 \mathrm{~mm}$, the ration between Ptm'-Ba'-A' was 6.11:12.2 which can be taken as 6:12 (i.e. 1:2), thereby the approximate vertical length from Ptm 'to $A$ ' was $18.36 \mathrm{~mm}$ which can be taken as $18 \mathrm{~mm}$ for a skeletal class I individual.

Whereas, ANS could be seen, $4.98 \mathrm{~mm}$ approximately 5 $\mathrm{mm}$ horizontally ahead of line $\mathrm{N}-\mathrm{N}$ perpendicular. With these millimetric parameters it would be easy to locate the point ANS.

\begin{tabular}{|c|c|c|c|c|c|c|c|}
\hline Sr. No. & ANB & $\begin{array}{c}\text { Ptm'- }^{\text {Ba' }} \\
\text { Ba }^{\prime}\end{array}$ & $\begin{array}{c}\text { Ba'- } \\
\text { ANS' }^{\prime}\end{array}$ & ANS'-A' $^{\prime}$ & $\begin{array}{c}\text { Ptm'- } \\
\text { Ba'A' }^{\prime}\end{array}$ & Ptm'-A' $^{\prime}$ & ANS-ANS' \\
\hline Average & 2.16 & 6.11 & 6.39 & 5.81 & $6.11: 12.2$ & 18.36 & 4.98 \\
\hline \multicolumn{8}{|c|}{ Table 1. Results and Observations } \\
\hline
\end{tabular}

\section{DISCUSSION}

It was observed that linear distance of Point ANS to $\mathrm{N}$ perpendicular (ANS') line was approximately half of the linear distance of Point Ba'-A'

Example 1: if the linear distance from Point Ptm'-Ba' is 5.5 $\mathrm{mm}$ and the linear distance from Point $\mathrm{Ba}^{\prime}-\mathrm{A}^{\prime}$ is $9 \mathrm{~mm}$, divide 9 $\mathrm{mm}$ into half i.e. $4.5 \mathrm{~mm}$. Mark this point as ANS on $\mathrm{N}$ perpendicular. From this point a perpendicular distance of 4.5 $\mathrm{mm}$ is Point ANS. Example 2: if the linear distance from Point Ptm'-Ba' is $6 \mathrm{~mm}$, while Ba'-A' is $12 \mathrm{~mm}$, Point ANS will be marked $6 \mathrm{~mm}$ ahead, from the midpoint between $\mathrm{Ba}^{\prime}-\mathrm{A}^{\prime}$ from line $\mathrm{N}$ perpendicular. Linear measurements from Point Ptm'$\mathrm{Ba}^{\prime}, \mathrm{Ba}^{\prime}-\mathrm{ANS}$, ANS'-A' were thus found to be proportionally equal with a ratio of 1:1:1.

Maxilla is most commonly seen affected in various craniofacial anomalies due to its direct attachment and close relation with the cranium as compared to the mandible which is thought to be an individual entity though affected secondarily. ${ }^{10,11}$ For any surgical outcome complete evaluation of the jaw clinically and cephalometrically is important. Due to underdeveloped maxilla or the quality of the radiographs when any landmark is not identified it becomes difficult to plan the treatment strategy and outcome.

The golden proportion for the aesthetic value is important not only for the extraoral parameters but also for the skeletal uniformity. Anyhow tipping of the palatal plane in clockwise or anticlockwise direction can affect the positioning of the point ANS. The following study can be considered to be one of its kind as there are no other parameters to replace point ANs while literature search did not have any alternative to replace point ANS for the cases with craniofacial anomaly in which the antero posterior length of the maxilla need to be evaluated.
This revisited landmark can be used as a substitute point where ANS is not identified on the cephalogram. The suitability and applicability of this revisited Point ANS needs further study to validate its reliability in other skeletal malocclusion and craniofacial anomalies.

\section{CONCLUSIONS}

Linear distance of Point ANS to $\mathrm{N}$ perpendicular (ANS') line was approximately half of the linear distance of Point $\mathrm{Ba}^{\prime}-\mathrm{A}$, while Point ANS is placed approximately $5 \pm 2 \mathrm{~mm}$ ahead of the line $\mathrm{N}$ perpendicular.

Financial or Other Competing Interests: None.

\section{REFERENCES}

[1] Jacobson RL, Jacobson A. Point a revisited. American J Orthod 1980;77(1):92-6.

[2] Rakosi T. Cephalometric landmarks, an Atlas of cephalometric radiology. Freiburg-im-Bresgua, Germany: Wolfe Medical Publication Limited. August 1978: p. 34-44.

[3] Berkowitz S. Cleft lip and palate: diagnosis and management. $2^{\text {nd }}$ edn. Springer- Verlag Berlin Heildelberg 2006.

[4] Noyes FB. Case report. Angle Orthod 1939;9:160-5.

[5] Hourany R, Aygun N, Santina CCD, et al. Silent sinus syndrome: and acquired condition. American Journal of Neuroradialogy 2005;26(9):2390-2.

[6] Cohen MM, Winer RA. Dental and facial characteristics in Down's syndrome (Mongolism). J Dent Res 1965;44(1):197-208.

[7] Grabb WC. The first and second branchial arch syndrome. Plastic and Reconstructive Surgery 1965;36(5):485-508.

[8] Gorlin R, Pindborg JJ, Cohen M Jr. Syndromes of the head and neck. $2^{\text {nd }}$ edn. New York: McGraw-Hill 1976.

[9] Kasatwar A, Borle R, Bhola N, et al. Prevalence of congenital cardiac anomalies in patients with cleft lip and palate - its implications in surgical management. Journal of Oral Biology and Craniofacial Research 2018;8(3):2414.

[10] Da Silva FOG, Normando AD, Filho Cl. Mandibular growth in patients with cleft lip and / or palate- the influence of cleft type. Am J Orthod and Dentofacorthop 1933;104(3):269-75

[11] Karia H, Shrivastav S, Karia AK. Three-dimensional evaluation of the airway spaces in patients with and without cleft lip and palate: a digital volume tomographic study. American Journal of Orthodontics and Dentofacial Orthopedics 2017;152(3):371-81. 